\section{Supplemental Lighting Orientation and Red-to-blue Ratio of Light-emitting Diodes for Greenhouse Tomato Production}

\author{
Paul Deram ${ }^{3}$ \\ Department of Bioresource Engineering, Macdonald Campus of McGill \\ University, 21111 Lakeshore Road, Ste-Anne-de-Bellevue, Quebec, H9X \\ 3V9, Canada
}

\section{Mark G. Lefsrud ${ }^{\mathbf{1}}$ and Valérie Orsat ${ }^{\mathbf{1 , 2}}$ \\ Department of Bioresource Engineering, Macdonald Campus of McGill University}

Additional index words. high-pressure sodium, intercanopy lighting, photosynthesis, supplemental lighting

\begin{abstract}
Current greenhouse supplemental lighting technology uses broad-spectrum high-pressure sodium lamps (HPS) that, despite being an excellent luminous source, are not the most efficient light source for plant production. Specific light frequencies in the 400- to 700-nm range have been shown to affect photosynthesis more directly than other wavelengths (especially in the red and blue ranges). Light-emitting diodes (LEDs) could diminish lighting costs as a result of their high efficiency, lower operating temperatures, and wavelength specificity. LEDs can be selected to target the wavelengths used by plants, enabling growers to customize the light produced, to enable maximum plant production and limit wavelengths that do not significantly impact plant growth. In our experiment, hydroponically grown tomato plants (Solanum lycopersicum L.) were grown using a full factorial design with three light intensities (high: $135 \mu \mathrm{mol} \cdot \mathrm{m}^{-2} \cdot \mathrm{s}^{-1}$, medium: $115 \mu \mathrm{mol} \cdot \mathrm{m}^{-2} \cdot \mathrm{s}^{-1}$, and low: $\left.100 \mu \mathrm{mol} \cdot \mathrm{m}^{-2} \cdot \mathrm{s}^{-1}\right)$ at three red $(661 \mathrm{~nm})$ to blue $(449 \mathrm{~nm})$ ratio levels $(5: 1,10: 1$, and 19:1). Secondary treatments for comparison were $100 \%$ HPS, $100 \%$ red LED light supplied from above the plant, $100 \%$ red LED light supplied below the plant, a 50\%:50\% LED:HPS mixture, and a control (no supplemental lighting). Both runs of the experiment lasted 120 days during the Summer-Fall 2011 and the WinterSpring 2011-12. The highest biomass production (excluding fruit) occurred with the 19:1 ratio (red to blue) with increasing intensity resulting in more growth, whereas a higher fruit production was obtained using the 5:1 ratio. The highest marketable fruit production (fruit over $90 \mathrm{~g}$ ) was obtained with the 50\%:50\% LED:HPS followed by 5:1 high and 19:1 high. Consistently the 5:1 high performed well in every category. LEDs have been shown to be superior in fruit production over HPS alone, and LEDs can improve tomato fruit production when mixed with HPS. LEDs provide a promising mechanism to enhance greenhouse artificial lighting systems.
\end{abstract}

Tomatoes are one of the most important horticultural crops in the world. According to Statistics Canada, tomato sales accounted for close to $50 \%$ of the total fruit and vegetable sales in the country in 2011 (Statistics Canada, 2011). Tomato sales in Canada reached \$496 million, an increase of 5.5\% since 2010 (Statistics Canada, 2011). Greenhouse production exceeded field-grown tomatoes in 1997,

Received for publication 30 Aug. 2013. Accepted for publication 8 Jan. 2014.

This work was supported by General Electric Lighting Solutions Canada and the Natural Sciences and Engineering Research Council of Canada (NSERC) (CRDPJ project no. 418919-11). We thank Claire Boivin for her tomato growing expertise.

${ }^{1}$ Associate Professors.

${ }^{2}$ Chair.

${ }^{3}$ To whom reprint requests should be addressed; e-mail paulderam@gmail.com. hours), and supplemental artificial lighting is required to maintain a consistent crop yield throughout the Canadian winters. Conventional greenhouse lighting systems use broad-spectrum light sources such as HPS or fluorescent lamps. LEDs have been shown to decrease artificial lighting costs to less than $25 \%$ of the cost of traditional artificial lighting as a result of their $75 \%$ higher electrical conversion efficiency (Gomez et al., 2013). HPS lamps were tailored for human vision and therefore are not ideally suited for plant growth (Bula et al., 1991).

Earlier research has shown that the most important wavelengths for photosynthesis are in the blue and red wavelengths; peaks in photosynthetic efficiency are found at 440 (blue), 620 (red), and 670 (red) nm ( $\pm 10 \mathrm{~nm}$ ) (McCree, 1972). The rapid improvement in LED technology has been driving research in plant production in recent years (Brazaitye et al., 2009). Xiaoying et al. (2012) reported new LEDs with a bandwidth of $\pm 15 \mathrm{~nm}$, permitting for much better focus on the most efficient wavelengths for photosynthesis. The wavelength specificity, small mass (less than $1 \mathrm{~g}$ each), small volume, relatively cool emitting temperature, longevity of over 100,000 h, and linear photon output are all characteristics that make LEDs better suited for crop production than earlier greenhouse lighting systems (Folta et al., 2005).

Different wavelengths of the light spectrum have been found to have specific effects on plant morphology, physiology, photosynthesis efficacy, and flowering capabilities (Menard et al., 2006). Although light is the primary source of energy for photosynthesis, it is also a vital regulator of many photosensory circuits in plants. Blue light and red light trigger different circuits and gene expression, which can have both positive and negative effects on the growth and development of plants (O'Carrigan et al., 2014). Thus, research is focusing more on proper combinations of light (Massa et al., 2008). Okamoto et al. (1996) reported that both red and blue light can be used by chlorophyll during photosynthesis and explained that blue light is beneficial to plant morphology and overall health. Blue light ( $450 \mathrm{~nm}$ ) has been shown to heavily suppress stem elongation in multiple plant species (Okamoto et al., 1996) but also increases plant biomass and fruit yield in tomato and cucumber plants (Menard et al., 2006). Hernández and Kubota (2012) reported that at the tomato seedling stage, red light is sufficient to grow tomato seedlings and that the addition of blue light is unnecessary. Overall, blue light is not as effective for photosynthesis as red light, because it inhibits leaf growth by reducing cell expansion and reduces the total amount of chlorophyll in the leaves (Goto, 2003). As a result of this lower efficiency, researchers tend to undervalue the use of blue light and not consider it in high proportions for plant growth (Goto, 2003). A lack of blue light has been shown to have adverse effects on plant morphology: low number of chloroplasts, lower thickness of cell walls, and low spongy mesophyll tissues 
(Goto, 2003). Boccalandro et al. (2012) show that blue light promotes leaf expansion, stomatal opening, and chloroplast relocation through phototropin activation in Arabidopsis and other higher plants. Blue light was shown to stimulate stomata opening and increase the rate of photosynthesis by up to $30 \%$ in some species (Menard et al., 2006). Blue light from LED sources was also shown to be highly efficient at protecting crop plants from many pathogens as well as increasing antioxidants and osmoprotectant production (Kim et al., 2013). Plant response to light from the red and the blue spectra has been documented extensively (Menard et al., 2006). The ratio of blue to red light is shown to be the most important factor when using LEDs, because having both blue light and red light increases plant biomass growth and fruit production by over $20 \%$ when compared with having only one of the wavelengths (Brazaityte et al., 2009; Goto, 2003; Lefsrud et al., 2008; Xiaoying et al., 2011, 2012).

This experiment used LED prototypes from General Electric Lighting Solutions Canada (Lachine, Quebec, Canada), where the overall goal of the project was to determine which ratio and intensity combinations best suit tomato plants for fruit production under greenhouse applications. Previous studies performed at McGill University (Martineau et al., 2012; Schwalb, 2013) have shown that the ratios of red to blue light used for this experiment increased plant photosynthetic rate at the seedling stage and this research would confirm that these same ratios result in improved fruit and biomass production for mature plants.

\section{Materials and Methods}

Tomato plants (S. esculentum cv. Trust were grafted onto $S$. hirsutum cv. Maxifort) (Ontario Plant Propagation, St. Thomas, Ontario, Canada) were obtained $55 \mathrm{~d}$ after seeding and were hydroponically grown in a greenhouse setting following similar culture methods to the industrial practices of Savoura (Les Serres Du St-Laurent Inc., Portneuf, Quebec, Canada) using a modified full-strength Hoagland nutrient solution (Savoura proprietary information) (Deram, 2013).

The air temperature ranged from $21.8 \pm$ $2.4{ }^{\circ} \mathrm{C}$ during the day and $16.9 \pm 3.4{ }^{\circ} \mathrm{C}$ during the night (average of both experimental runs). The LED light arrays were turned on from 0600 to $2200 \mathrm{HR}$ for a total photoperiod of $16 \mathrm{~h}$. The nutrient solution was supplied through drip irrigation (14257 Biofloral, Montreal, Quebec, Canada) for $3 \mathrm{~min}$ out of every $20 \mathrm{~min}\left(19 \mathrm{~L} \cdot \mathrm{h}^{-1}\right)$ for a total irrigation of $\approx 6 \mathrm{~L}$ per plant per day (based on $1 \mathrm{~mL}$ per $1 \mathrm{~J}$ of irradiance). The plants were pollinated by hand, shaking the flowers with a cotton-tipped swab three times a week. A central computer in the greenhouse controlled the lights, irrigation, and ventilation coupled with a misting system for cooling. Relative humidity was monitored but was not controlled. Average daily relative humidity reached a high of $82 \% \pm 5 \%$ and a low of $30 \% \pm 10 \%$ (average of both experimental runs).

The LED light arrays were prototypes $(1.78 \mathrm{~m} \times 8 \mathrm{~cm} \times 2 \mathrm{~cm})$ with wavelengths of $449 \mathrm{~nm}$ for blue light and $665 \mathrm{~nm}$ for red light. Twelve ratio and intensity-specific LED prototypes were used, nine of which were used to set up a full factorial with three ratios of red to blue $(5: 1,10: 1$, and 19:1) and three intensities (high: $135 \mu \mathrm{mol} \cdot \mathrm{m}^{-2} \cdot \mathrm{s}^{-1}$, medium: $115 \mu \mathrm{mol} \cdot \mathrm{m}^{-2} \cdot \mathrm{s}^{-1}$, and low: $100 \mu \mathrm{mol} \cdot \mathrm{m}^{-2} \cdot \mathrm{s}^{-1}$ ) measured and confirmed at the beginning and end of each replicate with less than $2 \%$ drift during replicates. The light sensor used was the underwater spherical quantum sensor (LI-193; Li-COR, Lincoln, NE); an explanation on why this sensor was chosen can be found in the "Results and Discussion" section. The remaining prototypes, used for further experimental treatments, were two $100 \%$ red light arrays (red top and red bottom at the high intensity of $135 \mu \mathrm{mol} \cdot \mathrm{m}^{-2} \cdot \mathrm{s}^{-1}$ ) and a 10:1 medium (for use in the 50\%:50\% LED:HPS, combined irradiance at $135 \mu \mathrm{mol} \cdot \mathrm{m}^{-2} \cdot \mathrm{s}^{-1}$ ). Three HPS lamps (Philips SON-T Master 600W, Amsterdam, The Netherlands) were used, one for the 50\%:50\% LED:HPS and two for the $100 \%$ HPS section $\left(135 \mu \mathrm{mol} \cdot \mathrm{m}^{-2} \cdot \mathrm{s}^{-1}\right)$. The control section did not have any supplemental lighting. The red bottom treatment lights were placed at the bottom of the section (at the level of the first leaves) and shone upward into the plant canopy, whereas the red top LEDs were placed at the top, similar to all other treatments.

A greenhouse section $(7.6 \mathrm{~m} \times 12 \mathrm{~m}$ set in a north-south orientation) with long wire mesh tables ( $1.2 \mathrm{~m}$ in height) was used. The tables were separated into 14 sections $(2 \mathrm{~m} \times$ $1 \mathrm{~m}$ ), each one for a specific light treatment. Three lamps were installed per section, making space for two rows of plants between them. The lamps were set at an intercanopy level ( $10 \mathrm{~cm}$ below the top of the plants) and raised weekly to maintain relative height, except for the red bottom treatment, where the lamps were kept at the height of the first leaves. Each section was surrounded by a double layer of $2.44 \mathrm{~m}$ high ( 8 feet) $80 \%$ shadecloth (8MK808; Harnois, St-Thomas, Quebec, Canada), preventing 96\% of light from passing through. A single layer of $2.44 \mathrm{~m}$ (8 feet) 60\% shadecloth (8MK608; Harnois) was installed above all of the sections during the first replicate (summer months) to simulate winter conditions.

Two experimental replicates, summer (July to Oct. 2011) and winter (Jan. to Apr. 2012), were performed with two harvest times, one at $70 \mathrm{~d}$ and one at $120 \mathrm{~d}$. Half the plants were randomly selected and harvested at $70 \mathrm{~d}$, and the remaining plants continued the experiment for the full $120 \mathrm{~d}$. A 2-month period was allotted between the experimental replicates to minimize the risk of pathogens carrying over. The location of each light treatment in the greenhouse was randomly allotted at the beginning of each experimental replicate. Eight plants (six during the second experimental replicate, because the Savoura plants were larger and the same plant density was kept) were placed in each section, in two rows, between the lamps. The individual plants were measured as individual replicates between seasons. The change in plant number (from eight to six) did not have any effect on the statistical analysis of the reported values.

At harvest, fresh weight was determined by separating and weighing both aerial plant biomass (the rooting system was discarded) and fruit biomass. All fruit greater than $2 \mathrm{~g}$ were counted and weighed (fruit under $2 \mathrm{~g}$ were included as plant biomass). Ripe fruit was harvested throughout the experiment at the first observed red pigmentation (considered ripe), counted, and individually weighed. Plants were pruned according to Savoura's methods (every 2 weeks, Savoura unpublished data) with fresh and dry biomass measured for each plant. The marketable fruit value was set at $90 \mathrm{~g}$ and is an internal standard for Savoura signifying marketable fruit. The fresh biomass harvested (aerial and fruit) was dried according to the ASABE (2007) standard with a temperature of $65{ }^{\circ} \mathrm{C}$ for no less than $72 \mathrm{~h}$ and subsequently weighed.

Main effects were analyzed by one-way analysis of variance with the standard TukeyKramer test $(\alpha \leq 0.05)$ applied to determine significant differences between treatments. The relationship between the experiment's dependent variables and treatments was determined by regression analysis. As a result of the strong constraints of the experiment (large plant variability, limited space, limited time, large number of different factors needing testing), the power of the statistical analysis was calculated post hoc to be between $10 \%$ and $38 \%$ depending on the quantity being tested.

\section{Results and Discussion}

The point source nature of the LED arrays makes it difficult to measure the light intensity with conventional light-measuring devices. Typical spectroradiometers and lightmeasuring devices are built to measure light levels from the sun or other light sources that disperse light in every direction (such as HPS lighting) and therefore are not as compatible with the LED arrays. A series of irradiance tests were performed with a range of different light measuring devices to find the most appropriate solution for measuring the LED point source arrays. All light measurements were taken at horizontal, vertical, and $45^{\circ}$ at three different heights and three points along the length of each light fixture. The first test was performed using a pyranometer (total solar radiation) (MP-100; Apogee Instruments, Logan UT) and a quantum meter (measures only the photosynthetically active radiation) (MQ-100; Apogee Instruments). It was found that the light measurement from both devices was variable (30\% differences in readings) under weighing blue light and over weighing red light (Apogee Instruments Inc., 2012a, $2012 \mathrm{~b}$ ); they may not properly report wavelengths outside the 460 - to 660 -nm range, and therefore they could not be used for the experiment. A spectroradiometer (BLACK-Comet 
Concave Grating Spectrometer; StellarNet Inc., Tampa, FL) was then tested. The spectroradiometer was much more reliable than the quantum meter and pyranometer, but the same problem with variability resulting from spatial position was found. The spectroradiometer was designed for conventional overhead light sources and only records light coming from directly above the sensor. The field of view of a typical spectroradiometer was shown to be $10^{\circ}$ (MacArthur et al., 2007). With adjustments to the positioning (directly facing the LED for the measurements), a light map could be created using the spectroradiometer, but it was still not as reliable as expected for measurements of the light received by the plants.

An underwater spherical quantum sensor (LI-193; Li-COR) was tested. The spherical quantum sensor was developed to capture light dispersion in underwater biological experiments by measuring the photon flux coming from all directions. This sensor was chosen as a result of its ability to record the photon flux coming from all directions, which was well suited for measuring the LED lighting in this experiment (because the LED arrays do not result in a wide dispersion of light). The measurements of the light from all angles above a theoretical horizontal surface resulted in no significant reduction in reported values. This underwater spherical light sensor was well adapted to the LED fixtures and gave us much more accurate measurements of the lighting with less than $5 \%$ variability between measurements. However, it should be noted that when the handle of the light sensor was parallel to the light source (or above the theoretical horizontal surface), the light measurement was $20 \%$ lower than when placed perpendicular to the light source. Despite the $20 \%$ loss in reading light perpendicular to the sensor, the underwater quantum sensor was found to be the most accurate sensor for this research and a well-adapted sensor to LED testing. No statistical difference was measured between the initial and final light readings or between the intensities of treatments at the same intensity level. The average daily light integral (solar and artificial) was $21 \mathrm{~mol} \cdot \mathrm{d}^{-1} \pm$ $37 \mathrm{~mol} \cdot \mathrm{d}^{-1}$ for the summer run and $42 \mathrm{~mol} \cdot \mathrm{d}^{-1} \pm$ $20 \mathrm{~mol} \cdot \mathrm{d}^{-1}$ for the winter run.

Results from the experiment revealed that the five highest number of fruit-producing light treatments were 5:1 high (385 fruit), 5:1 medium (358 fruit), 5:1 low (341 fruit), 19:1 high (315 fruit), and 100\% LED (310 fruit). The control was statistically significantly different from all five of the high producing treatments. The average number of fruit per plant is shown in Figure 1. The 5:1 ratio was the highest producing ratio from this experiment with all three intensities leading the ranking for most fruit produced. The 5:1 ratio being the highest fruit-producing ratio in this experiment agrees with research from Goto (2003) and Menard et al. (2006), who found that blue light promoted flowering and fruiting, but contradicts Miyashita et al. (1995), who reported that red light, and not blue light, would increase flowering. With regard to fruit mass, 5:1 high $(27.2 \mathrm{~kg}), 5: 1$ medium $(25.8 \mathrm{~kg}), 19: 1$ high $(24 \mathrm{~kg}), 50 \%: 50 \%$ LED:HPS $(23.3 \mathrm{~kg})$, and red top $(23.2 \mathrm{~kg})$ were the five highest treatments. No statistical differences were measured between any of the treatments with the exception of the control, which was statistically different from all five of the high producing treatments. The average fruit mass per plant is shown in Figure 2. The highest five treatments for marketable number of fruit were 50\%:50\% LED:HPS (with a total of 118 fruit over $90 \mathrm{~g}$ ), red top (115 fruit), 5:1 medium (113 fruit), 19:1 high (109 fruit), and 5:1 high (104 fruit). The highest five total marketable fruit mass were the same treatments but in a different order: 50\%:50\% LED:HPS with $17.4 \mathrm{~kg}$ followed by $5: 1$ high with $16.3 \mathrm{~kg}, 19: 1$ high with $16.2 \mathrm{~kg}$, red top with $15.8 \mathrm{~kg}$, and 5:1 medium with $15.6 \mathrm{~kg}$. Fifty percent:50\% LED:HPS was one of the highest producing treatments for marketable fruit and agrees with research from Menard et al. (2006) that shows that supplementing blue and red light to HPS creates much higher production than with HPS alone. The differences between the highest treatments were not statistically different, but all highest producing treatments were statistically different from the control. The average marketable fruit mass per plant is shown in Figure 3.

The high irradiance level was the highest producer for all ratios, both for vegetative biomass and for fruit production. As expected from the literature, higher intensities bring forth more production (McAvoy, 1984; Tennessen et al., 1994) with all ratios producing more under higher irradiance levels.

The five highest treatments for both fresh biomass and dry biomass were 19:1 high and red bottom and included the other 19:1 treatments (medium and low) and the 100\% red top. For fresh weight, they were 19:1 high had $37.8 \mathrm{~kg}$ followed by red bottom with $37.4 \mathrm{~kg}$, 50\%:50\% LED:HPS with $34.5 \mathrm{~kg}$, and 10:1 medium with $33.9 \mathrm{~kg}$. The average fresh biomass per plant is shown in Figure 4. For dry mass, 19:1 high had $2.8 \mathrm{~kg}$ followed by

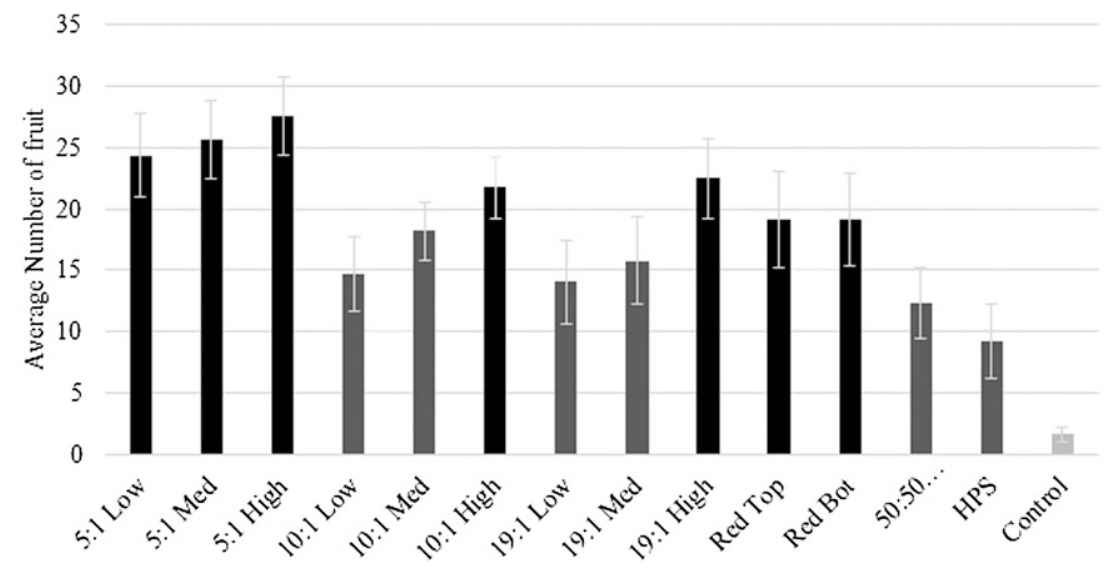

Fig. 1. Average number of fruit per plant per light treatment. The data were separated into three categories. Best: over 19 fruit (in black). Average: from seven to 19 fruit (in dark gray). Poor: under seven marketable fruit (in light gray). Statistically significant differences were observed between the best category and the poor category.

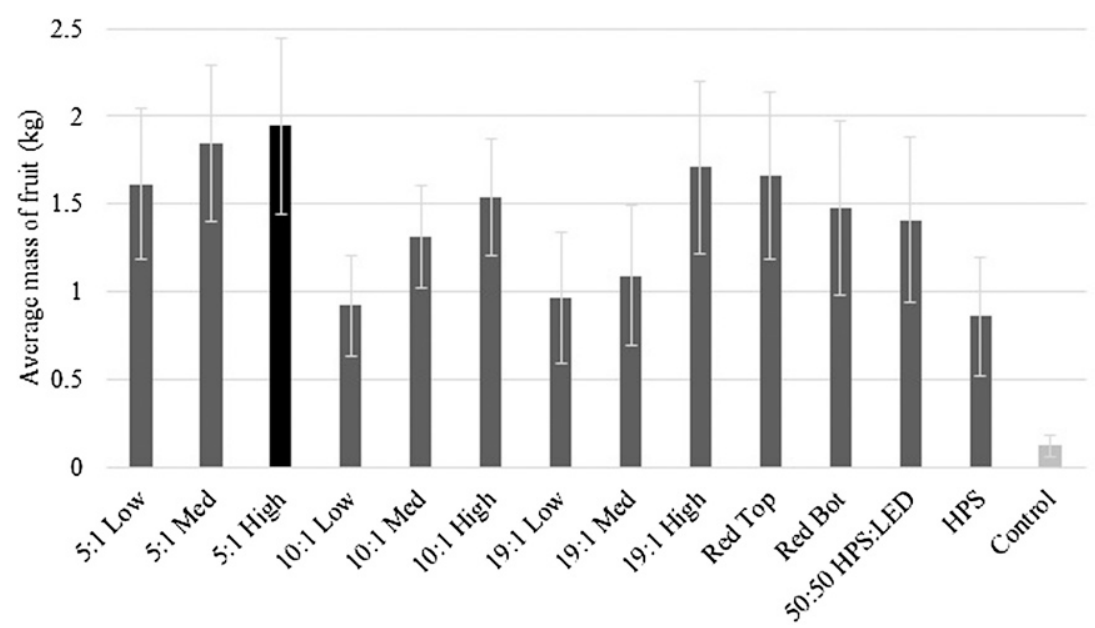

Fig. 2. Average fruit mass per plant $(\mathrm{kg})$ per light treatment. The data were separated into three categories. Best: over $1.9 \mathrm{~kg}$ of fruit (in black). Average: from $0.2 \mathrm{~kg}$ to $1.9 \mathrm{~kg}$ of fruit (in dark gray). Poor: under $0.2 \mathrm{~kg}$ of fruit (in light gray). Statistically significant differences were observed between the best category and the poor category. 
red bottom at $2.7 \mathrm{~kg}, 5: 1$ high at $2.5 \mathrm{~kg}$, and 19:1 medium at $2.5 \mathrm{~kg}$. This result is supported by the literature that shows that red light produces more biomass (Brown et al., 1995; Hoenecke et al., 1992), because all treatments with high red light were found consistently to be the highest. The largest fresh and dry vegetative biomass occurred with the 19:1 high LED.

A fruit mass-to-plant fresh biomass ratio was calculated as shown in Figure 5. The five highest ratio treatments were 5:1 low $(0.87$ fruit to biomass), 5:1 high (0.82), 5:1 medium (0.79), red top (0.75), and 10:1 high (0.71). The control ratio was 0.12 . All 5:1 intensity levels as well as 10:1 high, red top, and 50\%:50\% LED:HPS were found to be statistically different from the control treatment. The 5:1 ratio treatments (high, medium, and low) were shown to be statistically different from treatments 10:1 low and 19:1 low (the two lowest after control).

For the marketable fruit mass-to-plant fresh biomass ratio, the five highest treatments were red top (0.49), 5:1 high (0.49), 50\%:50\% LED:HPS (0.48), 5:1 low (0.49), and 5:1 medium (0.46). The control ratio was measured at 0.09 . Statistically significant differences were observed between the red top and 5:1 high treatments with the control only. Fruit-to-biomass ratio provides information on the amount of vegetative biomass the plant produced relative to fruit production. This ratio is important, because it shows how efficient the plant was at producing fruit from the resources given. A higher value is more desirable, because it shows that a higher proportion of the plant growth was turned into the marketable product.

The red top and the red bottom treatments were directly compared with each other. The major difference between the two treatments was the setup with the red bottom treatment lights placed at the bottom of the section and shone upward into the plant canopy, whereas the red top LEDs were placed at the top, similar to all other treatments. The red bottom had slightly less light levels than the red top. Overall, the red bottom section slightly underperformed when compared with the red top in fruiting categories but created more biomass. No statistical differences were measured between these two treatments. The differences between the two treatments are more pronounced toward the end of the run. These differences could be explained by the lower light levels or because the plants in the red bottom section grew more side stems and suckers close to the LED arrays and did not grow as tall (observed but not measured). However, no conclusions can be drawn from the statistics, and the production results were similar for both treatments. This result could suggest that the light coming from below was at least as beneficial as the light coming from above (Moss, 1964).

From the regression analysis of the factorial experiment, it can be reported that higher levels of light increased production, whereas increased levels of red light (relative to blue) resulted in less fruit:

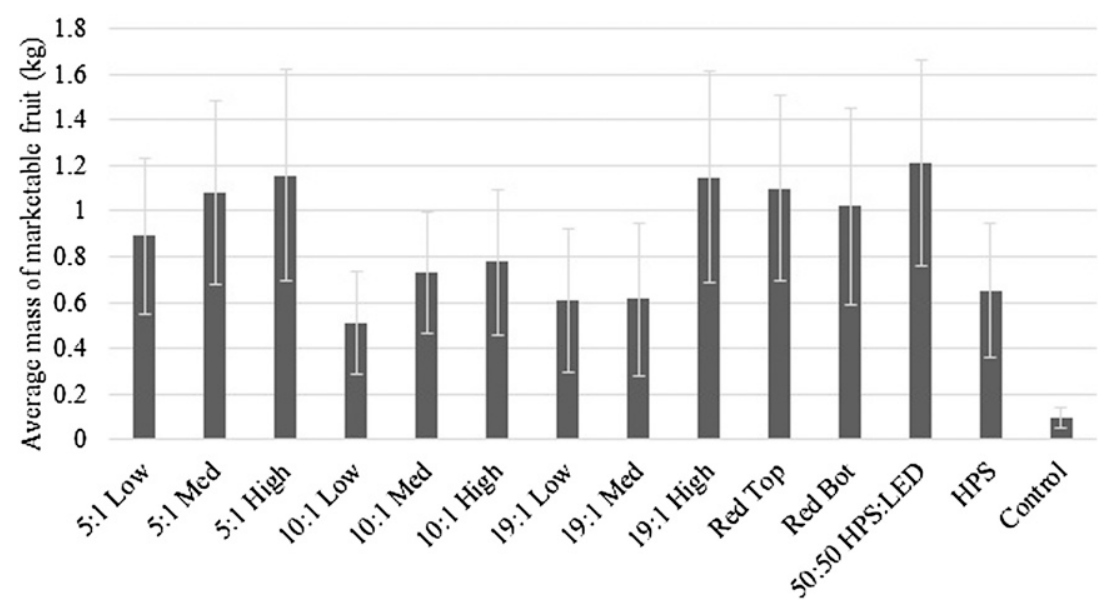

Fig. 3. Average marketable fruit mass per plant $(\mathrm{kg})$ per light treatment. No statistically significant differences were observed.

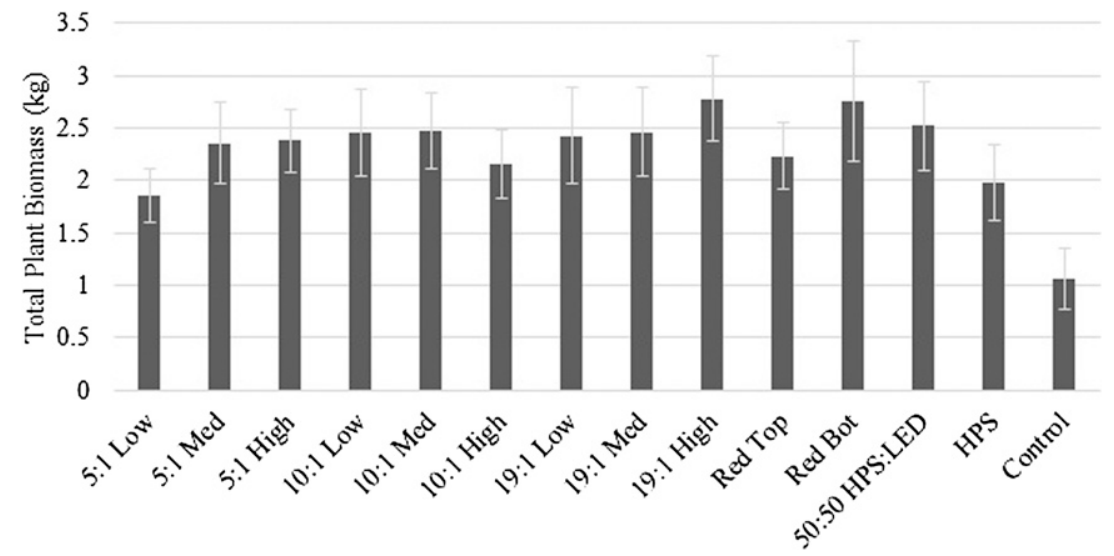

Fig. 4. Average fresh weight of plant biomass (excluding fruit) per light treatment (kg). No statistically significant differences were observed.

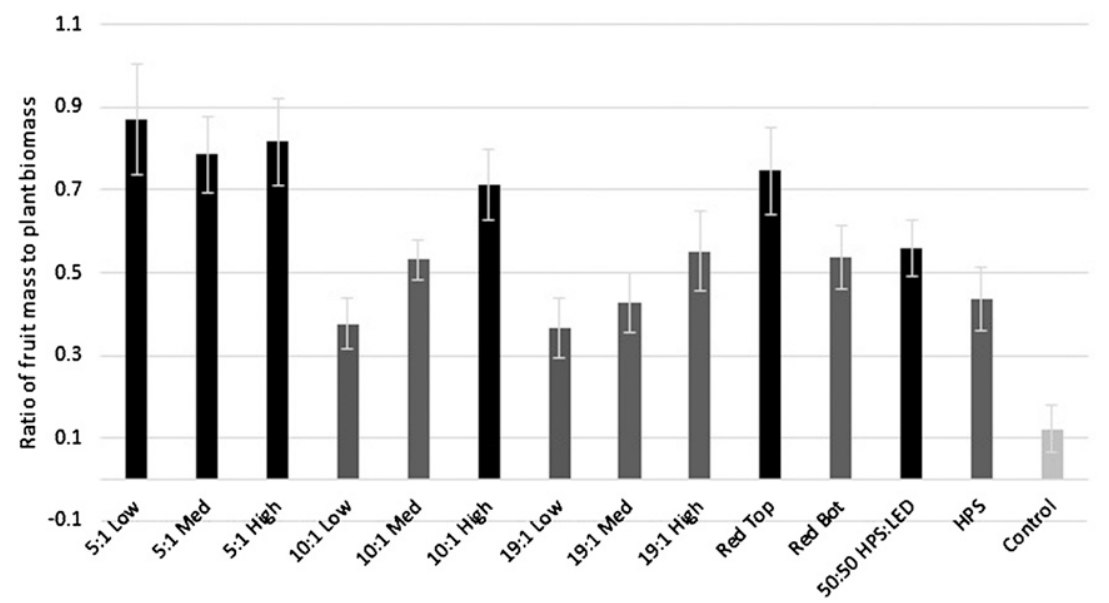

Fig. 5. Total fruit mass-to-plant biomass ratio per light treatment. Statistically significant differences between the best category and the poor category; also between the highest two (5:1 low and 5:1 high) and the treatments under 0.4 (10:1 low and 19:1 low).

$$
\begin{gathered}
\text { Number of Fruit }=23.9+\text { Intensity } * 0.12 \\
+ \text { Light Ratio } *(-4.5) \quad\left(\mathrm{R}^{2}=0.68\right)
\end{gathered}
$$

where intensity is the amount of light in the treatment $\left(100 \mu \mathrm{mol} \cdot \mathrm{m}^{-2} \cdot \mathrm{s}^{-1}\right.$ for low, 115 $\mu \mathrm{mol} \cdot \mathrm{m}^{-2} \cdot \mathrm{s}^{-1}$ for medium, $135 \mu \mathrm{mol} \cdot \mathrm{m}^{-2} \cdot \mathrm{s}^{-1}$ for high) and light ratio is the ratio of red light to blue light ( 1 for $5: 1,2$ for 10:1, and 3 for 19:1, chosen in sequence).

The regression analysis also indicated that increased levels of light resulted in increased biomass, and increased red 
light (relative to blue) resulted in more biomass:

$$
\begin{aligned}
& \text { Vegetative Fresh Biomass(in grams) } \\
& \begin{array}{l}
=1982.2+\text { Intensity } * 5.1 \\
\quad+\text { Light Ratio } * 426.3 \quad\left(\mathrm{R}^{2}=0.64\right)
\end{array}
\end{aligned}
$$

where intensity is the amount of light in the treatment, in $\mu \mathrm{mol} \cdot \mathrm{m}^{-2} \cdot \mathrm{s}^{-1}$ (100 for low, 115 for medium, 135 for high) and light ratio is the ratio of red light to blue light (1 for 5:1, 2 for 10:1, and 3 for 19:1).

\section{Conclusion}

Overall, it was shown that the highest producing LED treatments (5:1 high, 5:1 medium, 19:1 high, and 5:1 low) and 50\%:50\% LED:HPS consistently outperformed the HPS treatment alone, and thus these treatments can be considered an improvement over traditional HPS lighting for greenhouses. Although no significant differences were found between the higher performing treatments, 5:1 high consistently performed well in every category. As expected from the literature, it was found that an increase in light intensity brought higher production of both fruit mass and plant biomass, and an increase in red light increased biomass production and slightly lowered the amount of fruit production.

\section{Literature Cited}

Apogee Instruments Inc. 2012a. Apogee pyranometer technical information. 1 Nov. 2012. $<\mathrm{http}: / /$ www.apogeeinstruments.co.uk/apogeepyranometer-technical-information/>.

Apogee Instruments Inc. 2012b. Apogee quantum sensor technical information. 1 Nov. 2012. <http://www.apogeeinstruments.co.uk/ apogee-instruments-quantum-sensor-technicalinformation $/>$.

ASABE. 2007. Moisture measurement-Forages. American Society of Agricultural and Biological Engineers, Standard S358.2. ASABE, St. Joseph, MI.

Boccalandro, H., C. Giordano, E. Ploschuk, P. Piccoli, R. Bottini, and J. Casal. 2012. Phototropins but not cryptochromes mediate the blue light-specific promotion of stomatal conductance, while both enhance photosynthesis and transpiration under full sunlight. Plant Physiol. 158:1475-1484.

Brazaityte, A., P. Duchovskis, A. Urbonavičiūte, S. Samuoliene, J. Jankauskienè, V. Kazenas, A. Kasiulevičiūtè-Bonakère, Z. Bliznikas,
A. Novièkovas, K. Breivè, and A. Žukauskas. 2009. After-effect of light emitting diodes lighting on tomato growth and yield in greenhouse. Sodininkyste ir Daržininkyste 28:115126.

Brown, C., A. Schuerger, and J. Sager. 1995. Growth and photomorphogenesis of pepper plants under red light-emitting diodes with supplemental blue or far-red lighting. J. Amer. Soc. Hort. Sci. 120:808-813.

Bula, R., R. Morrow, T. Tibbitts, and D. Barta. 1991. Light-emitting diodes as a radiation source for plants. HortScience 26:203-205.

Cook, R. and L. Calvin. 2005. Greenhouse tomatoes change the dynamics of the North American fresh tomato industry. USDA ERR2:1-81.

Deram, P. 2013. Light-emitting-diode (LED) lighting for greenhouse tomato production. Master's thesis, McGill University, Montreal, Quebec, Canada.

Folta, K., L. Koss, R. McMorrow, H. Kim, J. Kenitz, R. Wheeler, and J. Sager. 2005. Design and fabrication of adjustable red-green-blue LED light arrays for plant research. BMC Plant Biol. 5.

Gomez, C., R. Morrow, C.B. Bourget, G. Massa, and C. Mitchell. 2013. Comparison of intercanopy light-emitting diode towers and overhead high pressure sodium lamps for supplemental lighting of greenhouse grown tomatoes. HortTechnology 23:93-98.

Goto, E. 2003. Effects of light quality on growth of crop plants under artificial lighting. Environ. Control in Biol. 41:121-132.

Hernández, R. and C. Kubota. 2012. Tomato seedling growth and morphological responses to supplemental LED lighting red:blue ratios under varied daily solar light integrals. Acta Hort. 956:187-194.

Hoenecke, M.E., R.J. Bula, and T.W. Tibbitts. 1992. Importance of 'blue' photon levels for lettuce seedlings grown under red-light-emitting diodes. HortScience 27:427-430.

Kim, K., H.S. Kook, Y.J. Jang, W.H. Lee, S. Kamala-Kannan, J.C. Chae, and K.J. Lee. 2013. The effect of blue-light-emitting diodes on antioxidant properties and resistance to Botrytis cinerea in tomato. J. Plant Path. Microbio. 4:203.

Lefsrud, M., D. Kopsell, and C. Sams. 2008 Irradiance from distinct wavelength lightemitting diodes affect secondary metabolites in kale. HortScience 43:2243-2244.

MacArthur, A.A., C. MacLellan, and T.J. Malthus. 2007. Determining the FOV and directional response of field spectroradiometers. The 5th EARSeL Workshop on Imaging Spectroscopy.

Martineau, V., M. Lefsrud, M.T. Naznin, and D.A. Kopsell. 2012. Comparison of light emitting diode and high pressure sodium light treatments for hydroponics growth of Boston lettuce. HortScience 47:477-482.

Massa, G., H. Kim, R. Wheeler, and C. Mitchell. 2008. Plant productivity in response to LED lighting. HortScience 43:1951-1956.

McAvoy, R. 1984. The use of high pressure sodium lights in greenhouse tomato crop production. Acta Hort. 148:877-888.

McCree, K. 1972. The action spectrum, absorption and quantum yield of photosynthesis in crop plants. Agr. Meteorol. 9:191-216.

Menard, C., T. Hovi, A. Gosselin, and M. Dorais. 2006. Developmental and physiological responses of tomato and cucumber to additional blue light. Acta Hort. 711:291-296.

Miyashita, Y., Y. Kitaya, and T. Kozai. 1995. Effects of red and far-red light on the growth and morphology of potato plantlets in-vitro: Using light emitting diode as a light source for micropropagation. Acta Hort. 393:189-194.

Moss, D.N. 1964. Optimum lighting of leaves. Crop Sci. 4:131-136.

O'Carrigan, A., E. Hinde, N. Lu, X.Q. Xu, H. Duan, G. Huang, M. Mak, B. Bellotti, and Z.H. Chen. 2014. Effects of light irradiance on stomatal regulation and growth of tomato. Environ. Exp. Bot. 98:65-73.

Ohashi-Kaneko, K., M. Takase, N. Kon, K. Fujiwara, and K. Kurata. 2007. Effect of light quality on growth and vegetable quality in leaf lettuce, spinach and komatsuna. Envrion. Control Biol. 45:189-198.

Okamoto, K.T.Y. and S. Takita. 1996. Development of plant growth apparatus using blue and red LED as artificial light source. Acta Hort. 440:111-116.

Schwalb, M. 2013. Measuring the short-term plant photosynthetic response to varying light quality using light emitting diodes (LEDs). Master's thesis, McGill University, Montreal, Quebec, Canada.

Smith, H. 1982. Light quality, photoperception, and plant strategy. Annu. Rev. Plant Physiol. 33:481-518.

Statistics Canada. 2011. Greenhouse, sod and nursery industries catalogue \# 22-202-x.

Tennessen, D., E. Singsaas, and T. Sharkley. 1994. Light-emitting diodes as a light source for photosynthesis research. Photosynth. Res. 39:85-92.

Xiaoying, L., G. ShiRong, X. ZhiGang, and J. XueLei. 2011. Regulation of chloroplast ultrastructure, cross-section anatomy of leaves, and morphology of stomata of cherry tomato by different light irradiations of light-emitting diodes. HortScience 46:217-221.

Xiaoying, L., G. ShiRong, C. TaoTao, X. ZhiGang, and J. XueLei. 2012. Regulation of the growth and photosynthesis of cherry tomato seedlings by different light irradiations of light emitting diodes (LED). Afr. J. Biotechnol. 11:61696177. 